\title{
AS IDEIAS NÃO MORREM: movimentos nas políticas curriculares e na formação docente
}

\author{
Alexandra Garcia \\ Universidade do Estado do Rio de Janeiro - UERJ, Brasil \\ Helena Amaral da Fontoura \\ Universidade do Estado do Rio de Janeiro - UERJ, Brasil
}

\begin{abstract}
Resumo
Neste artigo buscamos problematizar a relação entre as políticas voltadas para a formação que vêm ao encontro das políticas curriculares e de avaliação no que se refere à consolidação das estratégias de controle. Buscamos discutir as produções de resistências como movimentos que expressam a presença de ideias e de práticas que fogem às tentativas de controle da docência e às lógicas de centralização curricular. Argumentamos com base em Garcia, Alves e Negri, que as ideias que alimentam alternativas ao controle e à hegemonia persistem e emergem em diferentes experiências e produções políticaspráticas em torno dos currículos e da formação docente. Inspiradas metodologicamente nas pesquisas com os cotidianos e com narrativas, abordamos essas produções que nos levam a argumentar quanto à necessidade de estarmos vigilantes às tentativas de controle da docência e dos currículos ao mesmo tempo em que nos atentamos aos movimentos e produções insurgentes que permanecem ativos e se multiplicam mesmo diante de um contexto político desfavorável. Partimos de um cenário em que a convergência de políticas de controle chega à docência para chamar atenção para as resistências que se produzem para além do enfrentamento, trazendo transformações e alimentando outros caminhos com os currículos e com a formação docente que se deslocam de uma agenda oficial.
\end{abstract}

Palavras-chave: Políticas curriculares; Resistência; Processos formativos.

\begin{abstract}
In this article, we seek to problematize the relationship between policies focused on training that meet curriculum and evaluation policies with regard to the consolidation of control strategies. We aim to discuss the productions of resistances as movements that express the presence of ideas and practices that escape the attempts to control teaching and the logics of curricular centralization. We argue, based on Garcia, Alves and Negri, that the ideas that feed alternatives to control and hegemony persist and emerge in different experiences and practical political productions around curricula and teacher education. Inspired methodologically in research with daily life and narratives, we approach these productions that lead us to argue about the need to be vigilant to attempts to control teaching and curricula while being aware of insurgent movements and productions that remain active and multiply even in the face of an unfavorable political context. We start from a scenario in which the convergence of control policies comes to teaching to draw attention to the resistances produced beyond coping, bringing transformations and feeding other paths with curricula and teacher training that move away from an official agenda.
\end{abstract}

Keywords: Curriculum policies; Resistance; Formative processes.

ISSN 1645-1384 (online) www.curriculosemfronteiras.org

http:/ /dx.doi.org/10.35786/1645-1384.v21.n3.27 
You don't own me

You don't own me

\section{Primeiras aproximações...}

Nas conversas sobre estratégias de controle sobre a docência e as escolas ${ }^{2}$ cantamos junto com Bete Midler, Goldie Hown e Diane Keaton ${ }^{3}$, libertas de amarras convencionais, considerando o que sabem, o que produzem, no que acreditam, 'donas de si mesmas'. Nossos contrapontos falam de práticas e saberes docentes considerados, que inscrevem e se inscrevem em/nas políticas de existência cotidiana, que se gestam e gestam, também, movimentos de resistência a esse controle que vem externo e procura se impor a todo custo, nada que nos possua ou domine, mas que nos integre.

É importante pensar as resistências, que para nós melhor se expressam pela ideia de (re)existir, posto que é nas pequenas ações mobilizadas pela necessidade de existir cotidianamente, através das práticas docentes e curriculares, que as escolas, os professores e também as licenciaturas, resistem às lógicas e estratégias de controle caras aos avanços sobre a educação de um contexto político e cultural hostil aos direitos sociais. Essa posição expressa o entendimento de que muitas das práticas, ações e posicionamentos políticos que identificamos como resistências são tecidas como pautas e movimentos alternativos às políticas postas por agendas oficiais.

Ou seja, há uma criação de políticaspráticas (Oliveira, 2013) cotidianas que se alimenta nas redes de saberes e orienta-se politicamente nessas redes sem necessariamente ser produzida para responder às políticas ditas oficiais e mesmo para ser contra hegemônica, embora resultem em pontos de resistência. Nesse sentido, quando falamos em políticas e práticas produzidas nos currículos e processos formativos, estamos de acordo com o entendimento de que essas dimensões nos cotidianos são faces interligadas melhor entendidas pela ideia de que

Em primeiro lugar, é importante marcar a opção epistemológica pela ideia de que não há prática que não integre uma escolha política e que não há política que não se expresse por meio de práticas e que por elas não seja influenciada. Ou seja, o tema das políticas educacionais e das práticas cotidianas fica mais bem expresso como "políticaspráticas educacionais cotidianas", sem separação, sem a pressuposição de que são coisas diferentes (Oliveira, 2013, p. 376).

Em uma análise mais ampla do cenário em que a discussão nesse artigo se delineia, podemos partir do entendimento de que as estratégias que buscam controlar os processos pedagógicos nas escolas, os currículos e a ação docente foram se avolumando e se articulando nas duas últimas décadas no país com a influência cada vez mais forte das lógicas reformadoras sobre a educação (Freitas, 2014; Hypólito, 2010). Tais lógicas encontraram nas políticas de centralização curricular e na presença do neoconservadorismo no contexto 
político e cultural dos últimos quatro anos (Garcia e Gouvêa, 2018) solo fértil para avançarem sobre a docência e sobre as políticas de formação.

Nesse sentido, cabe problematizar a relação entre políticas voltadas para a formação que vêm ao encontro das políticas curriculares e de avaliação no que se refere à consolidação das estratégias de controle. Um dos fatores em comum nessa tríade é o reducionismo na compreensão de currículo e conhecimento que marca a era das políticas e práticas tipicamente gerencialistas das ações de Estado sobre a educação e que trazem intencionalidades de produzir regulações sociais (Hypólito, 2010).

As pesquisas no campo dos currículos e da formação docente vêm denunciando essas influências e suas implicações há mais de vinte anos, no entanto esse alerta, do ponto de vista das políticas curriculares, não impediu que tais lógicas se impusessem e se materializassem na Base Nacional Comum Curricular (BNCC), como pontuam Garcia, Baroni e Reis (2020, p. 81):

Mesmo diante do alerta de pesquisadores e de uma forte oposição dos professores, o encontro de aspectos relacionados a uma visão universalizante de conhecimento se inscreve de maneira subliminar no entendimento de conhecimento escolar. A compreensão eminentemente técnica e objetificante de currículo e conhecimento, além de interesses políticos e econômicos externos aos sujeitos e internos aos setores conservadores e a um nicho do mercado, convergiram para a promulgação da BNCC em 2017.

Não obstante os processos de centralização curricular voltados para a Educação Básica e aliados às avaliações em larga escala, que intensificam as estratégias de controle sobre os currículos e sobre as práticas docentes, a formação de professores se tornou o alvo seguinte no alinhamento político, como apontam análises do campo das pesquisas na Formação de Professores e também vemos expresso em notas de entidades científicas da área:

No atual cenário político vemos que os processos de centralização, padronização e controle se acentuam, com a articulação intrínseca da política nacional de formação a políticas de avaliação censitária com critérios de desempenho vinculado à lógica meritocrática. Ambas representam a retomada de proposições que julgávamos superadas como a pedagogia das competências, o neotecnicismo ideologizado e anacrônico e a imposição de uma padronização curricular reducionista, instrumental e esvaziada de significado social. A política atual propõe, de forma impositiva e veloz, o aligeiramento da formação e a precarização e flexibilização da profissão do magistério, que apenas favorece os interesses privatistas e mercantis da reforma empresarial da educação (Lino e Santos, 2021, p. 9).

Além disso, a Resolução n. ${ }^{\circ}$ 02/2019 recupera aspectos criticados pelas pesquisas em formação e no campo dos currículos, especialmente quanto a uma visão fragmentada dos conhecimentos e do próprio percurso de formação, sobretudo expressa pela separação de 
caminhos na formação docente que atinge os cursos de Pedagogia. Segundo tal resolução, nessas licenciaturas seria necessário que o aprofundamento de estudos se dividisse em três tipos de curso, dentre eles, um voltado para a formação de professores multidisciplinares para a Educação Infantil e outro para a formação de professores multidisciplinares para os Anos Iniciais do Ensino Fundamental. A fragmentação se expressa, ainda, pela separação entre docência e gestão, que ficaria destinada a especializações a posteriori e que indica uma concepção hierarquizada e desarticulada entre docência e gestão.

Nessa tríplice articulação entre formação, currículo e avaliação, notamos uma lógica já presente nos discursos circulantes na sociedade, sobretudo em políticas que usam o discurso da "qualidade" da educação para justificar a responsabilização docente na prestação de contas frente às metas estabelecidas para as escolas - às quais estaria associada a ideia de qualidade expressa pelos índices das avaliações em larga escala - e o desempenho insatisfatório dos estudantes nos exames. Essa centralidade no trabalho dos professores na Educação Básica vem se refletindo também no entendimento de que o suposto problema necessitaria ser equalizado pelo alinhamento no ensino superior dos saberes e competências docentes via padronização curricular da formação de professores.

Esse discurso das competências associado às compreensões sobre a docência e os conhecimentos necessários para a formação, fundamentalmente técnicos e instrumentais, sempre esteve presente nas disputas em torno dos currículos para a formação docente, tendo se intensificado com a influência neoliberal desde a década de noventa. No entanto, a presença e a força desses discursos estavam arrefecidas com o avanço das políticas para a formação desde os anos 2000, culminando com a resolução CNE/CP n²/2015.

Se tomamos como premissa a ideia de que as políticas são dinâmicas e estão em constante disputa por sentidos, assim como os contextos sociais e culturais nas quais germinam, precisamos ver que esse movimento estará presente em maior ou menor intensidade a depender dos contextos. Nesse momento, precisamos estar atentos a esse movimento que traz retrocessos para o campo da formação como desdobramentos dos retrocessos no campo dos currículos para a educação básica e como intensificação do controle sobre a docência. Ele avança e se expressa em um jogo discursivo que ao mesmo tempo que dá centralidade e protagonismo aos professores, o faz para justificar o controle e o esvaziamento político dos sentidos de formação, comprometendo o entendimento quanto à complexidade e peculiaridade dos saberes profissionais docentes. Retoma representações demeritórias sobre escola e docência e vai ao encontro de percepções concernentes aos interesses e visões mais ligados ao mercado, como expressam Garcia e Gouvêa (2018) ao discutirem o impacto para autonomia docente da articulação entre o ultraliberalismo e o conservadorismo no cenário político atual.

A ideia de que os discursos criam percepções de realidade, e que a busca por sua legitimação envolve uma disputa pelo poder de narrar uma dada "realidade" constituindo sua representação, pode ser útil para pensar nas representações demeritórias que se tornaram mais frequentes sobre a educação pública e o magistério, desde que esses se tornaram nichos de 
interesse e de investimento do mercado. Pautam-se em uma construção discursiva por pares de opostos que dicotomizam as percepções e compreensões pelos pares vilões $\mathrm{x}$ heróis, vitória x derrota, fracasso x sucesso. Acompanham os discursos demeritórios as "soluções" tais como pacotes pedagógicos, ênfases tecnológicas e agora mais recentemente processos de centralização curricular (Garcia e Gouvêa, 2018, p. 30).

Ao mesmo tempo que precisamos olhar criticamente e desinvisibilizar a presença e circulação de ideias que algumas vezes imaginamos terem ficado para trás e que voltam a nos assombrar e a evocar interpretações pessimistas e menos confiantes nas possibilidades de mudanças do cenário que vislumbramos, precisamos nos ater à desinvisibilização dos que criam os movimentos chamados de resistências. Nesse sentido, cabe identificarmos e visibilizarmos as contranarrativas aos sentidos hegemônicos circulantes ou mesmo respostas da prática às tentativas de se estabelecer uma hegemonia. Em parte, isso pode ser entendido a partir da ideia de que "a consistência ontológica dos indivíduos e da multidão permite olhar para a frente a cada emergência singular da vida como ato de resistência e de criação" (Negri, 1999, p. 1).

Nessa direção, Alves, em artigo que aborda uma trajetória de pensamentos e movimentos ligados à formação de professores e aos currículos no país, argumenta a possibilidade de pensarmos com as criações cotidianas a criação de alternativas e saídas, indo além da ideia de uma resistência como enfrentamento. A autora narra dois importantes movimentos nessa direção e defende que:

a agenda dos docentes e pesquisadores pode tecer movimentos e produzir acontecimentos que vão além da simples resistência aos equívocos e mesmo imposições de eventuais políticas oficiais, considerando a resistência sempre necessária, é claro. Em outras palavras, em um momento de grande crise política do país, trago no texto dois movimentos que atuaram na formação de docentes bastante relacionados um ao outro - e que permitem compreender que nunca são somente de resistência ao que é desenvolvido (e mesmo destruído) pela agenda oficial/governamental, mas que mostram a criação permanente de saídas outras, diferentes dessa agenda. (Alves, 2017, p. 3)

No encontro com o pensamento de Negri (2016), podemos pensar na insurgência que se mobiliza com os afetos, compreensões que derivam do pensamento spinoziano, e que tornam possível pensar um político na experiência democrática que produz o comum na e com a diferença. $\mathrm{O}$ autor identifica que tais produções têm relação com as paixões alegres e de uma política da vida. Algo que nos favorece considerar as resistências como criações dos movimentos de afirmação da vida cotidiana, que busca caminhos, na forma de práticas e sentidos não hegemônicos, (re)existindo.

Chamamos, assim, atenção para as emergências das formas de (re)existir em um contexto que se mostra hostil à docência. Trata-se de episódios em que a necessidade de existir cotidianamente nas escolas, em que professores da Educação Básica e professores dos 
cursos de licenciatura das instituições de ensino superior produzem práticas que afirmam sentidos políticos e éticos outros, não conformados às pautas do controle e centralização. Derivam do que no campo das pesquisas com os cotidianos se relaciona às criações e negociações de sentidos que permeiam as relações sociais e culturais, compondo os modos de vida comuns daqueles que operam táticas sutis de resistência ao produzir seu cotidiano (Certeau, 1994).

Assim, nos debruçamos em narrativas de processos e em narrativas docentes que trazem essas (re)existências, inspirados em modos de pesquisar os cotidianos atentos aos fazeressaberes dos praticantes (Certau, 1994) da docência nas escolas, redes públicas e cursos de licenciatura, em busca das ideias que expressam resistência à hegemonia e apontam deslocamentos das estratégias de controle sobre a docência e centralização curricular que vão para além da hegemonia e do ato intencional de resistir como contrapor-se ao instituído, portanto, se fazendo como práticas instituintes que correm de forma concomitante às tentativas de controle. Trabalhamos na combinação entre os princípios de valorização e percepção do que produzem os praticantes no campo das pesquisas com os cotidianos, agregada à pesquisa que envolve narrativas de processos de resistência a lógicas hegemônicas de controle sobre os currículos e sobre a formação docente, para com elas identificar e pensar a sobrevivência das ideias que germinam as resistências.

Metodologicamente nos identificamos com a exploração, estudo e sistematização de narrativas docentes, entendendo que

O espaçotempo dos encontros e narrativas docentes oportuniza a troca de experiências e a produção coletiva de saberes, interroga certezas que se mantinham repousadas sob a produção de práticas curriculares e compreensões naturalizadas de conhecimentos. Narrar é dar nome e forma às experiências, a partir do que nelas nos provoca contar. (Garcia e Gouvêa, 2018, p. 39)

\section{Sobre formação: quando eu sou dono/a de mim}

Falar sobre formação docente que possibilite uma reflexão na ação pode ser muito desafiador. Chamamos alguns autores com quem já dialogamos para auxiliar nessa tarefa. Com Nóvoa (1992) compreendemos a importância da abordagem das propostas de formação a partir de três eixos: a pessoa do professor e sua experiência, a profissão e seus saberes e a escola e seus projetos. Consideramos que a prática reflexiva é essencial para a profissão de professor, assim como a pesquisa. Entendemos, contudo, nesse sentido, que a as práticas mobilizam o processo reflexivo, necessitando que esse processo tenha espaço para acontecer de forma coletiva como práticas de formação contínua. Assim, reflexão e pesquisa são duas questões que se complementam, pois, o professor pesquisador é aquele que se pergunta e reflete sobre a sua prática, que assume a sua própria realidade escolar como pesquisa, reflexão. Prática a acontecer entre pares, dialogicamente, fortalecendo assim o desenvolvimento do trabalho coletivo. 
Saberes mobilizados por professores em sala de aula apontam a existência de uma epistemologia característica do trabalho docente. Trazemos a contribuição de Tardif (2000) com os estudos sobre prática profissional, que não se restringe a uma aplicação de conhecimentos universitários. Na verdade, ela seria a síntese de uma racionalidade onde os saberes universitários dividem espaço com a intuição, a criatividade, a sensibilidade, a improvisação e a rotina profissional. Para o autor, os saberes mobilizados pelos professores em seu trabalho cotidiano advêm de sua história de vida, de sua memória escolar, dos conhecimentos adquiridos em sua formação profissional e de sua experiência de trabalho.

Dialogando com Tardif (2002) quando pensamos na necessidade da interlocução nos saberes docentes dos aspectos teóricos, inclusive aqueles presentes nas práticas e dos aspectos mais técnicos, verificamos que a questão do saber dos professores não pode ser separada das outras dimensões do ensino e nem do estudo do trabalho realizado pelos professores de profissão. A questão do saber profissional é situada no contexto mais amplo do estudo da profissão docente, de sua história, de sua condição na escola e na sociedade. Segundo o autor, não se pode falar do saber sem estabelecer uma relação com o contexto do trabalho, pois "o saber é sempre o saber de alguém que trabalha alguma coisa no intuito de realizar um objetivo qualquer" (Tardif, 2002, p.11).

Considera ainda o autor que o saber docente é social porque é partilhado por um grupo de professores que trabalham em uma mesma organização e estão sujeitos a uma estrutura coletiva de trabalho. Esse saber está vinculado a um sistema que garante a sua legitimidade e orienta sua definição e utilização. E como o professor trabalha com sujeitos, o seu saber se manifesta através das relações estabelecidas com seus alunos. Além disso, o que os professores ensinam e a maneira de ensinar evoluem com o tempo e com as mudanças sociais, portanto o saber dos professores é um processo que se constrói ao longo de sua carreira profissional.

Na profissão docente, a relação cognitiva com o trabalho é acompanhada de uma relação social: os professores utilizam os saberes produzidos por um grupo, oriundos de uma instituição, incorporados por um mecanismo social (currículos, formação, instrumentos de trabalho). Além de plural, o saber é também temporal, pois é adquirido no contexto de uma história de vida e de uma carreira profissional. Antes de ensinarem, os futuros professores vivem aproximadamente dezesseis anos nas salas de aula e nas escolas, ou seja, já sabem algo sobre o que é ensino devido à sua história escolar anterior. Esse saber é muito forte, persiste através do tempo, pois nesse período são adquiridas crenças, representações e certezas sobre a prática do trabalho do professor que, muitas vezes, a formação universitária não consegue ressignificar.

Ouvindo Freire (2002, p.32), temos a ideia de que ser pesquisador faz parte da natureza da prática docente, não é uma qualidade ou forma de atuar acrescentada à de ensinar, pois para ele "não há ensino sem pesquisa e pesquisa sem ensino". Ao refletir sobre sua prática, o professor está questionando suas verdades e certezas, constatando e intervindo, e nesse movimento, ele educa e se educa.

Assim como Zeichner (2000), entendemos que a reflexão sobre o fazer docente é uma condição política fundamental da formação do professor, sendo que a sua formação reflexiva 
se vincula à luta pela construção da justiça social e intelectual no país. Investigar a docência, identificando o professor como produtor de conhecimentos referentes à profissão que exerce, sua prática, colocando-a em plano de destaque, e seus saberes da experiência como elementos desencadeadores para reflexões, torna-se, portanto, de fundamental importância para a compreensão do processo de ensino-aprendizagem, para o desenvolvimento de ações de formação que contribuam para o desenvolvimento de profissionais reflexivos e para um ensino de qualidade para a população.

Tardif (2002) destaca ainda a necessidade de repensar a formação, levando em conta os saberes dos professores e as realidades de seu trabalho cotidiano. Segundo o autor, essa ideia vem sendo discutida em muitos países, expressando a vontade de encontrar nos cursos uma nova articulação entre os conhecimentos produzidos pelas universidades a respeito do ensino e os saberes desenvolvidos pelos professores em suas práticas cotidianas. Em parte, essa é a ideia que alimenta a proposta expressa por pesquisadores no campo do currículo e no campo da Educação Fundamental, das relações diálogos entre as escolas e universidades. Proposta que tem inspiração nas discussões de Zeichner (2010) quanto às relações entre universidade e escola nas pesquisas e na formação docente.

É nessa direção que se reitera a pertinência de pensar os processos formativos com licenciaturas a partir da possibilidade de se apropriar das especificidades da atividade docente no contato com aqueles que já se encontram na profissão, considerando que "o principal desafio para a formação de professores, nos próximos anos, será o de abrir um espaço maior para os conhecimentos práticos dentro do próprio currículo" (Tardif, 2002, p.241).

Essa constatação demonstra que propostas de formação necessitam contemplar a estreita ligação entre a formação teórica e a prática profissional dos professores no sentido da compreensão dos saberes docentes e consequentemente para pensar a produção desses saberes com os currículos. Para isso, se faz necessário unir pesquisa e ensino. Sua proposta é que a pesquisa universitária veja os professores de profissão não como objetos de pesquisa, mas como sujeitos do conhecimento, como colaboradores, como pesquisadores. As pesquisas desenvolvidas nas universidades devem valorizar os professores de profissão e, ao mesmo tempo, promover sua formação continuada, buscando a construção de conhecimentos e a valorização da prática educativa, repensando assim a própria formação acadêmica.

Segundo Tardif e Lessard (2007), a experiência dos professores é marcada por dilemas próprios do trabalho interativo, é paradoxal e portadora de ambiguidades. Ensinar é assumir tensões, dilemas sem uma solução específica, é fazer escolhas que produzem consequências e custos, imprevisíveis ou mesmo contrários às intenções iniciais. $\mathrm{O}$ estudo desses autores e nossa própria experiência no campo da formação de professores mostram que, dos percursos de formação vivenciados na vida acadêmica, na estrutura curricular dos cursos, às experiências concretas de docência, inúmeras questões emergem, tornando-se conflitivas para os/as jovens professores/as.

Diante desse quadro, consideramos que os primeiros anos de inserção profissional são decisivos para o desenvolvimento e a consolidação da carreira docente, pois: 
(...) a mediocridade das condições de trabalho, os efeitos frustrantes da rotina e da normalização impostas (pelo programa, pela rigidez da compartimentalização, de tempos e de espaços, pelos processos estereotipados de trabalho e avaliação institucionalmente aceitos, etc) associando-se aos problemas resultantes do baixo nível remunerativo, às múltiplas solicitações exteriores, levam o professor a responder às suas necessidades de afirmação e expansão fora da escola (Cavaco, 1995, p.180).

Muitos professores abandonam a carreira, principalmente no início de sua vida profissional, devido em parte à frustração causada pelo contato com a realidade das salas de aula do ensino público, das condições de trabalho, dos baixos salários e da desmotivação de alunos e colegas mais antigos na profissão. A complexidade do trabalho profissional docente, sobretudo frente à produção cotidiana dos currículos, traz exigências para pensar os processos de formação que são temas de pesquisa e de ações no campo, bem como, se articulam às discussões mais recentes do debate sobre os currículos nas diretrizes para a formação de professores.

Ressaltamos que a ideia de ter um 'modelo' de formação contradiz a proposta do presente texto, já que problematizamos as políticas e todas as práticas decorrentes de uniformizações, de dimensões autoritárias e homogeneizadoras. Qualquer expectativa de controle social a partir de propostas formativas deve ser repudiada por formadores, considerando as contribuiçõos dos autores acima como possibilidades de somar a currículos em que a tônica seja coconstrutiva, democrática e plural, de acordo com os contextos em que se dão.

\section{Movimentos insurgentes...}

Há experiências acontecendo que nos sinalizam para insurgências contra um discurso autoritário e homogeneizador.

Fontoura (2019) apresenta o relato de um estudo exploratório com o objetivo de compartilhar reflexões acerca do processo de reformulação do curso de Pedagogia da Faculdade de Formação de Professores (FFP/UERJ). Desvela um processo construído coletivamente, que buscou produzir um curso de acordo com as diretrizes, mas principalmente em consonância com docentes e discentes da instituição, com a realidade conjuntural e com princípios de uma educação democrática, pública e de qualidade, marca da instituição em tela. Iniciativas como a apresentada falam de possibilidades de articular políticas trazidas por governos com realidades possíveis em cursos reais com propostas democráticas e factíveis.

Garcia e Leite (2019), ao discutirem o processo de reformulação de um curso de Pedagogia, explicitam que o referido processo possibilitou vários trabalhos coletivos e trouxe à tona conflitos entre diferentes compreensões e perspectivas de formação, currículo e conhecimento. Esse processo e o 'desenho' do curso refletem os diálogos e as negociações que expressam a materialização dos caminhos encontrados quanto às demandas dos docentes, 
dos alunos, assim como as potencialidades que percebemos nos currículos produzidos no cotidiano.

Problematizar as políticas de governo no que se refere aos contextos formação docente é importante para refletirmos sobre as compreensões dos currículos e dos conhecimentos nos processos de formação. A educação como um processo intencional e institucional, de responsabilidade de uma sociedade e Estado como um compromisso público é uma tarefa complexa que como tal exige uma formação profissional. Esse aspecto torna relevante o debate em torno das proposições de políticas para a formação docente ao mesmo tempo em que traz à tona as disputas ligadas às compreensões de docência, currículos, conhecimentos na/da formação, como também provoca pensar os sentidos de educação no contexto de um projeto político de sociedade que implica tanto a disputa entre ideias e propósitos, como o reconhecimento de que estando em maior ou menor destaque, as ideias contraditórias não morrem. Elas muitas vezes permanecem menos audíveis, se tornando mais intensas sempre que os contextos políticos e culturais favorecem que ecoem.

Isso se refere a pensarmos a vigilância que se torna necessária em termos de acompanhamento e avaliação de políticas públicas face aos riscos sempre presentes de ideias e ideais menos democráticos, mais conservadores e que buscam a hegemonia como estratégia de controle social, como também na latência dos possíveis, dos deslocamentos, das criações que fogem a essas lógicas e que emergem em narrativas das práticas cotidianas.

Ao considerarmos a questão da resistência ao controle sobre a docência e os currículos frente às políticas voltadas para a formação docente, há que se considerar que tais processos não se findam em um texto, um tempo ou no intervalo cronológico das políticas governamentais. Há que se considerar também a necessidade de não recair no equívoco de relacionar o texto de uma política pública com o intervalo de um governo, buscando a historicidade dessa política e os movimentos e disputas que ela contém para além das letras do texto. Muitas vezes as palavras indicam rotas e desvios para sentidos culturais, para visões políticas e para trajetórias nas quais as políticas são gestadas.

Quando falamos em políticas educacionais, mais especificamente em políticas curriculares, precisamos lembrar que os processos de tramitação e a gestação de um texto, por vezes, envolvem anos de debate, avanços, retrocessos e instâncias diversas pelas quais ideias e composições das políticas, até se materializarem em um texto, tramitam. Como afirmamos que as ideias não morrem, precisamos também considerar os envolvidos na produção do que se materializa como texto de uma política pública e do que vai sendo gestado no contexto político, acadêmico, histórico e cultural dos debates em torno dos currículos, da formação e da docência - nosso foco nesse artigo.

Um marco para a consolidação dos debates e mudanças foi a implementação da Lei de Diretrizes e Bases da Educação Nacional (Lei 9394/96). A LDBEN (artigo 61, parágrafo único) tratou dos fundamentos da formação docente, que deveriam ser amparados em uma "sólida formação básica", na "associação entre teorias e práticas, mediante estágios supervisionados e capacitação em serviço", com no mínimo 300 horas de prática de ensino, e no "aproveitamento da formação e experiências anteriores, em instituições de ensino e em outras atividades" (BRASIL, 1996). 
Em 2015 tivemos aprovada a Resolução CNE/CP 02/2015 que definiu as Diretrizes Curriculares Nacionais para a formação inicial em nível superior (cursos de licenciatura, cursos de formação pedagógica para graduados e cursos de segunda licenciatura) e para a formação continuada. Tal resolução reflete questões e lutas históricas no campo das pesquisas quanto às políticas voltadas para a formação e quanto aos currículos na formação de professores, sobretudo naquilo que se relaciona às conexões entre formação docente e políticas de valorização do magistério. Um dos aspectos presentes nessa diretriz, que merece ser destacado, é o entendimento de prática quando se trata dos saberes docentes e dos processos formativos.

A questão da prática como central à formação que está presente nesta resolução remete a uma compreensão mais ampla e relacionada à práxis, relação estabelecida no campo dos movimentos pela formação dos profissionais da educação e exposta no documento do Comitê Nacional Pró-Formação do Educador de 1983, conforme abordado por Alves (2015, p. 69):

desde o início, o movimento tem entendido que só pode haver uma discussão geral, encaminhando para uma prática de formação conjunta dos vários profissionais da educação sobre a ideia de que "a docência constitui a base da identidade profissional de todo educador".

Como o prazo inicial de adequação dos cursos à diretriz de 2015 era o ano de 2017 e como a cobrança por essa adequação gerou desde 2016 uma maior movimentação nos cursos de licenciatura em torno das discussões e proposições curriculares dos cursos face à diretriz, o contexto político nacional que se encontrava em crise após o golpe jurídico-parlamentar que resultou no impeachment da presidenta Dilma Rousseff alimentou o burburinho de que se tratava de uma política de controle sobre os cursos e sobre a docência, própria do avanço do pensamento neoliberal sobre a educação e ligada ao governo Michel Temer. No entanto, quando olhamos para o histórico em torno da produção dessa diretriz, como já mencionado, e para as instâncias que envolverem sua discussão e promulgação, sobretudo considerando a composição do Conselho Nacional de Educação (CNE), vamos notar a presença de intelectuais ligados ao campo da política educacional e das políticas de formação identificados politicamente com as tendências socialistas que marcaram as políticas públicas gestadas durante os governos em que o Partido dos Trabalhadores esteve no poder.

Os conselheiros são tradicionalmente nomeados a partir de indicações das entidades da sociedade civil na área de Educação. A composição do CNE é organizada através de mandatos dos conselheiros para um período de quatro anos. $\mathrm{O}$ conselho é formado pelas Câmaras de Educação Básica e de Educação Superior e conta, cada uma delas, com doze conselheiros escolhidos e nomeados pelo presidente da República. A composição do CNE contou com alguns conselheiros com esse perfil e mesmo após a revogação da nomeação feita por Dilma Rousseff em maio, feita por Temer em junho de 2016, deixou como legado importantes resoluções no campo das políticas educacionais, dentre elas a que definiu as Diretrizes Nacionais para a formação inicial e continuada de professores em nível superior (CNE/CP, no 2/2015). 
Conforme já destacaram Garcia e Leite (2019) com relação ao legado das Diretrizes de 2015, importantes aspectos, como o enfrentamento da fragmentação, aparecem no texto e expressam o avanço político que se materializa nas referidas diretrizes, fruto das ideias que foram gestadas com os movimentos pela formação de professores ao longo dos anos e as inúmeras pesquisas acadêmicas.

Dizem as autoras:

Considerando o Curso de Pedagogia e suas diferentes áreas de atuação, sobretudo quanto à necessária articulação entre as diversas áreas de conhecimento que são próprias da docência nos anos iniciais da Educação Básica, a crítica da fragmentação entre essas áreas é uma questão central para pensar a formação e atuação do egresso desse curso, que tem como base a formação docente. (Garcia e Leite, 2019, p. 551/552)

Além da questão de egressos, apontada pelas autoras acima, com relação ao que defendemos nesse artigo sobre a permanência das ideias e o modo como elas alimentam políticaspráticas que implicam em resistências ao controle e à hegemonia, também temos outros movimentos de resistências cotidianas. São movimentos que emergem na problematização da centralização curricular em espaços distintos como escolas, Fóruns de Educação, Associações de Profissionais de Educação, dentre outros.

Conforme viemos discutindo ao longo do presente texto, as políticas de formação se produzem também com o legado de outras políticas e ações que se consolidam nas práticas das escolas e redes públicas em diálogo com o necessário investimento na autonomia docente e na formação continuada como um elemento central às políticas públicas que investem na melhoria da Educação Básica como um compromisso contínuo. Nesse sentido, existem experiências no país que nos permitem vislumbrar esse movimento e acreditar que as ideias podem estar mais desfavorecidas em determinados momentos e contextos políticos, históricos ou culturais, mas elas continuam a germinar, a alimentar outras composições e ações políticas.

Recentemente vimos estados e municípios revendo seus documentos de orientação curricular em face às exigências de que a legislação relativa ao currículo se adequasse à BNCC. No estado do Rio de Janeiro essa exigência desencadeou um forte movimento de resistência à centralização curricular e em defesa da autonomia das redes, escolas e docentes, protagonizado pela articulação entre entidades científicas da área de educação pertencentes ao Fórum Estadual de Educação do Estado do Rio de Janeiro (FEERJ) e professores da Educação Básica.

O processo nos permite considerar que a produção de políticas, e mesmo dos textos que se relacionam a políticas específicas e com maior nível de controle previsto, são e podem ser tensionadas e disputadas quanto aos sentidos e direções que expressam. Garcia, Baroni e Reis (2020) narram e problematizam o processo que, segundo as autoras, expressou: 
um processo vivido no estado do Rio de Janeiro em torno dessa questão maior que mobilizou uma articulação que podemos considerar constitutiva de um momento histórico na formulação e disputa política. Nesse contexto, abordamos a discussão em torno da produção dos currículos e das políticas públicas referentes aos anos iniciais do ensino fundamental, na perspectiva expressa em parecer elaborado por professores-pesquisadores da educação básica que integraram a equipe que analisou o texto preliminar, intitulado Documento Curricular do Estado do Rio de Janeiro (Dcerj). Nesse sentido, situamos a discussão considerando a relevância da articulação estabelecida na condução do processo entre o Conselho Estadual de Educação (CEE-RJ) e o Fórum Estadual de Educação do Estado do Rio de Janeiro (Feerj). O encaminhamento integrou entidades científicas participantes do Feerj, professores da educação básica e universidades na avaliação, influenciando a produção de uma política pública. (Garcia, Baroni, Reis, 2020, p. 79)

Dentre os aspectos que o movimento nos permite considerar está a necessária articulação entre escolas e universidades, expressa pela mobilização de docentes da educação básica por parte das entidades científicas para a análise do documento preliminar apresentado ao Conselho Estadual de Educação (CEE) e que embora também redigido por uma equipe integrada por docentes de universidades e da educação básica, guardava maior alinhamento com a centralização curricular e apresentava compreensões de docência, escola e currículo problematizada pelos professores que fizeram sua análise.

Atendendo à proposta do presente trabalho de articular diferentes contribuições para desvelar as resistências nem sempre na perspectiva de enfrentamento, mas como resultantes de redes de saberes, de experiências de praticantes que alimentam posicionamentos políticos outros, trazemos a narrativa de uma docente da Rede Municipal de Juiz de Fora/MG que atua como Coordenadora Pedagógica e professora dos anos iniciais da Educação Básica:

Com a lei do piso nacional Lei $n^{\circ} 11.738$ de 16/7/2008, a PJF instituiu a redução da carga horária dos profissionais da Educação no município. Desta forma, os professores PRA e PRB (anos iniciais e anos finais), passaram a trabalhar efetivamente na sala de aula 13 horas e 20 minutos e o restante 6 horas e 40 minutos como atividades extraclasses que consistem em planejamentos e formação. Já os coordenadores pedagógicos (supervisores/ orientadores) e direção escolar tiveram a carga reduzida para 14 horas e 40 minutos e o restante do horário também deverá ser utilizado para planejamento e formação, contando ao todo 22 horas de trabalho.

Além desse tempo, há também uma reunião para planejamento coletivo que foi nomeada de "reunião pedagógica". Essa reunião foi instituída e regulamentada pela Lei Municipal de $\mathrm{n}^{\mathrm{o}} 11.169$, de 22 de junho de 2006, que trata sobre o pagamento de adicional ao servidor do quadro de magistério. Tal valor incide em $10 \%$ sobre o salário dos profissionais de educação. (Professora Maria da Conceição Brandt da Luz, Rede municipal de Juiz de Fora/MG, 2021) 
Em relação aos ataques mais diretos que visam estabelecer estratégias de controle desde o processo de formação, também notamos uma movimentação significativas das Instituições de Ensino Superior (IES) que estiveram por cerca de dois anos debruçadas sobre as propostas curriculares e políticas de formação nas licenciaturas, fazendo valer a necessária autonomia dos cursos e instituições na construção das propostas curriculares para a formação de professores.

Além das notas de entidades, algumas contando com IES públicas como signatárias dos pedidos de revogação da Resolução 2/2019, que instituiu a BNC-Formação, vimos um movimento específico se delinear em resposta às ameaças à descaracterização dos cursos de Pedagogia.

A criação dos movimentos e fóruns em defesa dos cursos de Pedagogia, ação iniciada com a mobilização de coordenadores/ex-coordenadores de cursos de Pedagogia e pesquisadores envolvidos com o debate dos currículos desses cursos em IES públicas em alguns estados e potencializada com o movimento de iniciativa da ANFOPE que consistiu em uma agenda discussões em defesa da Pedagogia e da Formação de Professores no mês de abril, mês da mobilização, se entendeu por outros meses com a adesão de outras entidades e a criação de fóruns estaduais.

Dentre os Fóruns Estaduais, está o Fórum de Mobilização e Defesa do Curso de Pedagogia do Estado do Rio de Janeiro. O Fórum é integrado pelas principais universidades públicas do Rio de Janeiro e pela PUC-Rio, e as instituições organizadoras, a UFF, a UERJ, a UFRJ, a UFRRJ, a PUC-Rio e a UNIRIO. O fórum foi promotor de diferentes atividades desde sua criação e lançamento no mês de abril de 2021. Dentre as atividades, sempre remotas em função da pandemia e do isolamento social, foi organizada uma live com Próreitores de Graduação de três universidades públicas do estado, UERJ, UFF e UFRJ, para debater o edital Edital No 35, de 21 de junho de 2021 e a portaria 412 que impelem à adesão à BNC-Formação.

A existência e as ações desse Fórum resultam da confluência dos debates desenvolvidos nas instituições e nos cursos de Pedagogia quando da discussão que gestou a reformulação dos currículos desses cursos, motivada pela adequação à resolução $\mathrm{CNE} / \mathrm{CP}, \mathrm{n}^{\circ}$ 2/2015. Como já destacamos, por ser uma resolução que refletia lutas históricas do campo, levou as universidades a se debruçarem sobre suas propostas e a produzirem discussões mais amplas quanto às políticas de formação docente, tendo resguardadas a necessária autonomia na construção de suas propostas curriculares para tanto.

Também foi campo fértil para a organização de debates interinstitucionais que aproximaram os cursos, sobretudo através de suas coordenações, e estenderam o debate a docentes e discentes, além de propiciar mudanças significativas nas resoluções institucionais quanto às compreensões de docência, currículo e formação compatíveis com o legado das pesquisas e movimentos pela formação docente.

Essa mobilização fortaleceu politicamente os cursos e tornou possível que viessem a se auto organizarem na proposição de um Fórum em Defesa dos Cursos de Pedagogia frente aos ataques à formação, expressos pela revogação da diretriz de 2015 e pela aprovação de uma nova diretriz, de perfil mais conservador e de influências tecnicistas, que expressa um 
reducionismo na compreensão dos saberes e do trabalho docente e uma visão curricular instrumental, e também de perfil utilitário, compatível com o que se apresenta na BNCC.

Além desse Fórum, vimos durante o mês de abril de 2021 surgirem outros Fóruns estaduais com propósitos semelhantes e a criação de um movimento nacional que reune os fóruns dos diferentes estados com vistas a discutir os currículos e as políticas voltadas para a formação e estender esse debate a um público mais amplo, sobretudo de docentes e discentes dos cursos de Pedagogia no país. O principal veículo de debate e disseminação das discussões vem sendo a realização de lives organizadas mensalmente pelos fóruns estaduais.

\section{Considerações (in)conclusivas}

Refletir sobre currículo e formação docente não é tarefa simples, especialmente quando estamos em processo de mudança curricular determinado por lei, e para o qual está posto o desafio de propor caminhos outros para cursos em andamento. Pensar mudanças em cursos de licenciatura não pode ser desvinculada da apreciação da complexidade das relações sociais em que se inserem as questões relacionadas a esse processo, os contextos dos cursos em tela, o que se considera como conhecimentos necessários para formar professores e ainda a realidade de muitas formações em que processos burocráticos e elitizados se constituem tônicas.

A partir do exposto, trazemos algumas ponderações, na linha de reafirmar a centralidade da docência em qualquer opção quando pensamos as políticas e produções curriculares em diferentes níveis. Essa compreensão na relação entre a centralidade da docência na produção curricular e dos processos formativos que possam corroborar, nesse sentido, a necessária autonomia docente frente às políticaspráticas curriculares, se coloca desde a educação básica ao ensino superior. Ignorar o papel de professores nas implementações necessárias e urgentes de políticas educacionais efetivas é e sempre será um atestado de óbito nas referidas políticas. Professores e professoras são atores e autores na intrincada tarefa de coproduzir a educação, que entendemos necessariamente em uma perspectiva democrática e pública.

Apontamos no presente texto alguns caminhos que reconhecemos como possíveis, no que em geral se denomina como "micro", com professores em suas salas de aula subvertendo políticas que tendem ao conservadorismo, à massificação, ao nivelamento, à padronização.

Vimos também iniciativas de esferas comumente identificadas como "macro", como a criação de fóruns em que haja discussão, as decisões sejam tomadas coletivamente, movimentos organizados em resposta à asfixia proposta pelas políticas já mencionadas, que buscam em última análise regular e engessar processos democráticos e participativos em todas as instâncias.

A contribuição mais significativa desse ensaio é chamar atenção para os movimentos de resistência cotidiana, tanto de professores em suas escolas e salas de aula como de organizações de profissionais de educação que ousam sonhar com políticas curriculares que privilegiem atitudes solidárias na construção de uma sociedade mais justa e fraterna, no âmbito de um processo educacional que promova esses valores humanos construídos. 
Sobretudo entendendo que essas resistências não emergem necessariamente do enfrentamento, mas da produção cotidiana que se alimenta nas redes de afetos, políticas e de saberes que tecem as práticas e os possíveis da docência e dos currículos.

Assim, cabe ressaltar a impossibilidade de pensar as políticas de formação tendo em vista propostas de processos formativos e de docência que tendam à padronização ou centralização de currículos para a formação de professores.

Compreendemos e enfatizamos a importância de agir propositivamente em contextos desafiadores, como o que temos hoje em nosso país e no mundo. Buscar mudanças locais, identificando o que das normas legais pode ser positivado, nos ajuda a criar laços de união contra as propostas reacionárias produzidas por máquinas governamentais retrógadas, a serem combatidas, enfrentadas, com o que sabemos fazer de melhor: educação de qualidade para todos.

\section{Agradecimentos:}

As autoras agradecem à Fundação Carlos Chagas de Amparo à Pesquisa (FAPERJ) e ao CNPq pelo fomento concedido para nossas pesquisas.

\section{Notas:}

1. Disponível em https://www.youtube.com/watch?v=YJmRAieU9AI.

2. Esta publicação é fruto de pesquisas realizadas com o apoio FAPERJ através dos Editais Cientista do Nosso Estado e Jovem Cientista do Nosso Estado (03/2017) e com apoio do CNPq (Edital Universal).

3. Filme: The First Wives Club (filme americano de 1996, dirigido por Hugh Wilson, baseado na obra de Olivia Goldsmith).

\section{Referências}

ALVES, N. Alternativas de formação de professores para a educação básica: novos caminhos. In: ALVES, N; GARCIA, A; OLIVEIRA, I. Nilda Alves: Praticantepensante de cotidianos. Belo Horizonte: Autêntica, 2015. p.65-84

ALVES, Nilda Guimarães. Formação de docentes e currículos para além da resistência. Revista Brasileira de Educação, v. 22 n. 71, 2017, p. 1-18.

BRASIL. Constituição (1988). Constituição da República Federativa do Brasil. Brasília, DF: Câmara dos Deputados, 1988.

BRASIL. Lei de Diretrizes e Bases da Educação Nacional, no 9394, de 20 de dezembro de 1996.

BRASIL. Resolução CNE/CP n ${ }^{0}$, de $\mathbf{1}^{\mathbf{0}}$. de julho de 2015. Define as Diretrizes Curriculares Nacionais para a formação inicial em nível superior (cursos de licenciatura, cursos de formação pedagógica para graduados e cursos de segunda licenciatura) e para a formação continuada. Brasília, DF, 01 jul.2015.

CAVACO, Maria Helena. Ofício do professor: o tempo e as mudanças. In: NÓVOA, A.(org.). Profissão professor. Portugal: Porto Editora, 1995. p.155-191. 
CERTEAU, Michel: A invenção do cotidiano: 1. Artes de fazer. Petrópolis: Vozes, 1994.

FREIRE, Paulo. Pedagogia da autonomia: saberes necessários à prática educativa. São Paulo: Paz e Terra, 25. ed., 2002.

FONTOURA, H.A. Desafios da formação docente: o curso de Pedagogia da

Faculdade de Formação de Professores (FFP/UERJ). Form. Doc., Belo Horizonte, v. 11, n. 21, p. 57-70, mai./ago. 2019a. Disponível em https://revformacaodocente.com.br/index.php/rbpfp/article/view/229/204. Acesso em junho de 2021.

FREITAS, L. C. Os reformadores empresariais da educação e a disputa pelo controle do processo pedagógico na escola. Educação e Sociedade 35 (129), 1085, 2014.

GARCIA, A; BARONI, P; REIS, G. Movimentos na produção de políticas curriculares do estado do Rio de Janeiro: pensando a qualidade a partir das escolas. Em Aberto, v. 33 n. 109, 2020.

GARCIA, Alexandra; GOUVÊA, Tânia da Costa. Furando "a grande onda"? Tensões e sentidos de docência e currículos frente ao conservadorismo. Edição Especial: Conservadorismos: políticas e educação. Revista Communitas, v. 2, p. 27-46, 2018.

GARCIA, A.; LEITE, V. As políticas de formação docente e Curriculares de um curso de pedagogia: em defesa da articulação de conhecimentos e da produção coletiva. Revista Formação em Movimento, v. 02, p. 557582, 2019.

HYPOLITO, Álvaro M. Políticas curriculares, Estado e regulação. Educação e Sociedade. vol.31, n.113, p. 1337-1354, out./dez., 2010.

LINO, L. A; SANTOS, A. M. M. Editorial. Formação em Movimento. v.3, i.1, n.5, p. 7-15, jan./jun. 2021.

NEGRI, Antonio. Espinosa. Subversivo e Outros Escritos. Belo Horizonte: Autêntica, 2016.

NEGRI, Antonio. SPINOZA Filósofo da "Ética" é um antídoto à apologia atual da resignação. Herói do povo pós-moderno. Folha de São $\quad$ Paulo. https://www1.folha.uol.com.br/fsp/mais/fs28029905.htm . Acesso em 20.07.2021.

NÓVOA, Antonio. Formação de professores e profissão docente. In: NÓVOA, António (org.). Os professores e a sua formação. Lisboa: Publicações Dom Quixote, 1992.

OLIVEIRA, Inês B. CURRÍCULO E PROCESSOS DE APRENDIZAGEMENSINO: Políticaspráticas Educacionais Cotidianas. Currículo sem Fronteiras, v. 13, n. 3, p. 375-391, set./dez. 2013.

TARDIF, Maurice. Saberes profissionais dos professores e conhecimentos universitários: elementos para uma epistemologia da prática profissional dos professores e suas consequências em relação à formação para o magistério. Revista Brasileira de Educação, Campinas, n. 13, p. 5-24, jan./abr, 2000.

TARDIF, Maurice. Saberes docentes e formação profissional. Petrópolis, RJ: Vozes, 2002.

TARDIF, Maurice; LESSARD, Claude. O trabalho docente: elementos para uma teoria da docência como profissão de interações humanas. $3^{\mathrm{a}}$ ed. Petrópolis, RJ: Vozes, 2007.

ZEICHNER, K. M. Formação de professores: contato direto com a realidade da escola. Presença Pedagógica, v. 6, n. 34, p. 5-15, jul./ago. 2000.

ZEICHNER, K. Repensando as conexões entre a formação na universidade e as experiências de campo na forma-ção de professores em faculdades e universidades. Educação, Santa Maria, v. 35, n. 3, p. 479-504, set./dez. 2010.

\section{Correspondência}

Alexandra Garcia: Professora Associada Universidade do Estado do Rio de Janeiro. Professora permanente do Programa de Pós-Graduação em Educação - processos formativos e desigualdades sociais FFP/UERJ 
e do Programa de Pós-Graduação em Educação PROPEd/UERJ. Coordenadora do Grupo de Pesquisa e extensão: Diálogos escolas-universidade: processos de formação docente e a produção dos currículos nos cotidianos.

E-mail: alegarcialima@ hotmail.com

Helena Amaral da Fontoura: Professora Titular Departamento de Educação Faculdade de Formação de Professores Universidade do Estado do Rio de Janeiro. Professora permanente do Programa de PósGraduação em Educação - processos formativos e desigualdades sociais FFP/UERJ.

E-mail: helenafontoura@gmail.com

Texto publicado em Currículo sem Fronteiras com autorização dos autores. 